\title{
MRI follow-up after magnetic resonance-guided focused ultrasound for non-invasive thalamotomy: the neuroradiologist's perspective
}

\author{
Vera C. Keil ${ }^{1}\left(\mathbb{D} \cdot\right.$ Valeri Borger $^{2} \cdot$ Veronika Purrer $^{3} \cdot$ Simon F. Groetz $^{1} \cdot$ Lukas Scheef $^{4} \cdot$ Henning Boecker $^{4} \cdot$ \\ Hans H. Schild ${ }^{4}$. Christine Kindler ${ }^{3}$. Angelika Schmitt ${ }^{4}$. Laszlo Solymosi ${ }^{1}$ • Ullrich Wüllner ${ }^{3}$. Claus C. Pieper ${ }^{4}$
}

Received: 5 February 2020 / Accepted: 7 April 2020 / Published online: 3 May 2020

(C) The Author(s) 2020

\begin{abstract}
Purpose Magnetic resonance-guided focused ultrasound (MRgFUS) systems are increasingly used to non-invasively treat tremor; consensus on imaging follow-up is poor in these patients. This study aims to elucidate how MRgFUS lesions evolve for a radiological readership with regard to clinical outcome.

Methods MRgFUS-induced lesions and oedema were retrospectively evaluated based on DWI, SWI, T2-weighted and T1weighted 3-T MRI data acquired 30 min and 3, 30 and 180 days after MRgFUS ( $n=9$ essential tremor, $n=1$ Parkinson's patients). Lesions were assessed volumetrically, visually and by ADC measurements and compared with clinical effects using non-parametric testing.

Results Thirty minutes after treatment, all lesions could be identified on T2-weighted images. Immediate oedema was rare $(n=$ 1). Lesion volume as well as oedema reached a maximum on day 3 with a mean lesion size of $0.4 \pm 0.2 \mathrm{~cm}^{3}$ and an oedema volume $3.7 \pm 1.2$ times the lesion volume. On day 3, a distinct diffusion-restricted rim was noted that corresponded well with SWI. Lesion shrinkage after day 3 was observed in all sequences. Lesions were no longer detectable on DWI in $n=7 / 10$, on T2weighted images in $n=4 / 10$ and on T1-weighted images in $n=4 / 10$ on day 180 . No infarcts or haemorrhage were observed. There was no correlation between lesion size and initial motor skill improvement $(p=0.99)$. Tremor reduction dynamics correlated strongly with lesion shrinkage between days 3 and $180(p=0.01, R=0.76)$.

Conclusion In conclusion, cerebral MRgFUS lesions variably shrink over months. SWI is the sequence of choice to identify lesions after 6 months. Lesion volume is arguably associated with intermediate-term outcome.
\end{abstract}

Keywords Magnetic resonance imaging $\cdot$ Essential tremor $\cdot$ Parkinson disease $\cdot$ High-intensity focused ultrasound ablation

$\begin{array}{ll}\text { Abbreviations } \\ \text { AC-PC } & \text { Anterior commissure-posterior commissure } \\ \text { CI } & \text { Confidence interval } \\ \text { ET } & \text { Essential tremor } \\ \text { ICC } & \text { Intraclass coefficient }\end{array}$

Vera C. Keil

vera.keil@ukbonn.de

1 Department of Neuroradiology, University Hospital Bonn, Venusberg-Campus 1, 53127 Bonn, Germany

2 Department of Neurosurgery, University Hospital Bonn, Venusberg-Campus 1, 53127 Bonn, Germany

3 Department of Neurology, University Hospital Bonn, Venusberg-Campus 1, 53127 Bonn, Germany

4 Department of Radiology, University Hospital Bonn, Venusberg-Campus 1, 53127 Bonn, Germany
MPRAGE Magnetization prepared-rapid gradient echo

MRgFUS Magnetic resonance-guided focused ultrasound

PD Parkinson's disease

Vim Ventral intermediate (thalamic) nucleus

\section{Introduction}

Magnetic resonance-guided focused ultrasound (MRgFUS) for incisionless cerebral lesional therapy in tremor patients is increasingly gaining interest.

The MRgFUS system delivers energy via sonic elements to a deep brain location in order to thermally create a millimetresized strategic lesion. In tremor patients, the target location is currently most often the ventral intermediate nucleus (Vim) of the thalamus. MRI allows for lesion positioning/localisation, as well as temperature control during the procedure. The 
functional effects of the procedure can clinically be evaluated before a permanent cavity is created; thus in case of unwanted side effects, the lesion position can still be modified. To create a permanent lesion, local temperatures above $54{ }^{\circ} \mathrm{C}$ are maintained over several seconds. However, techniques may vary, and lesions may also be achieved at lower temperatures and different energy application techniques, which influence lesion sizes [1-3].

Although MRgFUS is a more recent method to treat movement disorders, several thousand patients have already been treated worldwide. Radiologists therefore may be confronted with patients after MRgFUS therapy, and thus should have knowledge on lesion development after the procedure [2, 4-11].

Based on an extended image analysis from the day of treatment until 6 months post-intervention, this study evaluated thalamic lesions after MRgFUS in ET and PD patients. Particular emphasis was put on the suspected position of Vim versus actual position of the lesion, and also the clinical presentation after intervention.

\section{Methods}

\section{Summary of the MRgFUS procedure}

The MRgFUS procedure at our institution is performed with the Exablate Neuro 4000 (InSightec, Haifa, Israel) integrated into a 3-T MRI system (GE Discovery 750, GE Healthcare, Milwaukee, WI, USA). Patients are awake during the so-called sonications (ultrasound applications), which allows a real-time evaluation of the clinical ultrasound effects. In all patients, the thalamic Vim was unilaterally treated. If the treatment effect is based on targeting the Vim itself or nearby fibre tract structures is at present subject of debate [8]. In accordance with the literature, the Vim centre was defined to be on the level of the anteriorposterior commissure (AC-PC) line and $14 \mathrm{~mm}$ lateral to it. The anterior-posterior position was one quarter of the total AC-PC line distance anterior of the PC (Fig. 1) [12]. This target however is only intended as a starting point for trial sonications of lower energy leaving no permanent lesion. Lesions were eventually produced based on the spot of the test sonication that showed the best clinical improvement. The number of (test) sonications, the necessity of energy delivered to achieve a certain temperature and the peak temperature itself are highly individual, but are protocoled for case management. A typical sonication lasts 14 to $20 \mathrm{~s}$ depending on the energy that needs to be delivered.

\section{Patients}

Ten patients were included in this retrospective observational study: nine with essential tremor (ET) and one with tremordominant Parkinson's disease (PD). Six were men and four women with a mean age $69.7 \pm 8.6$ years. All had undergone

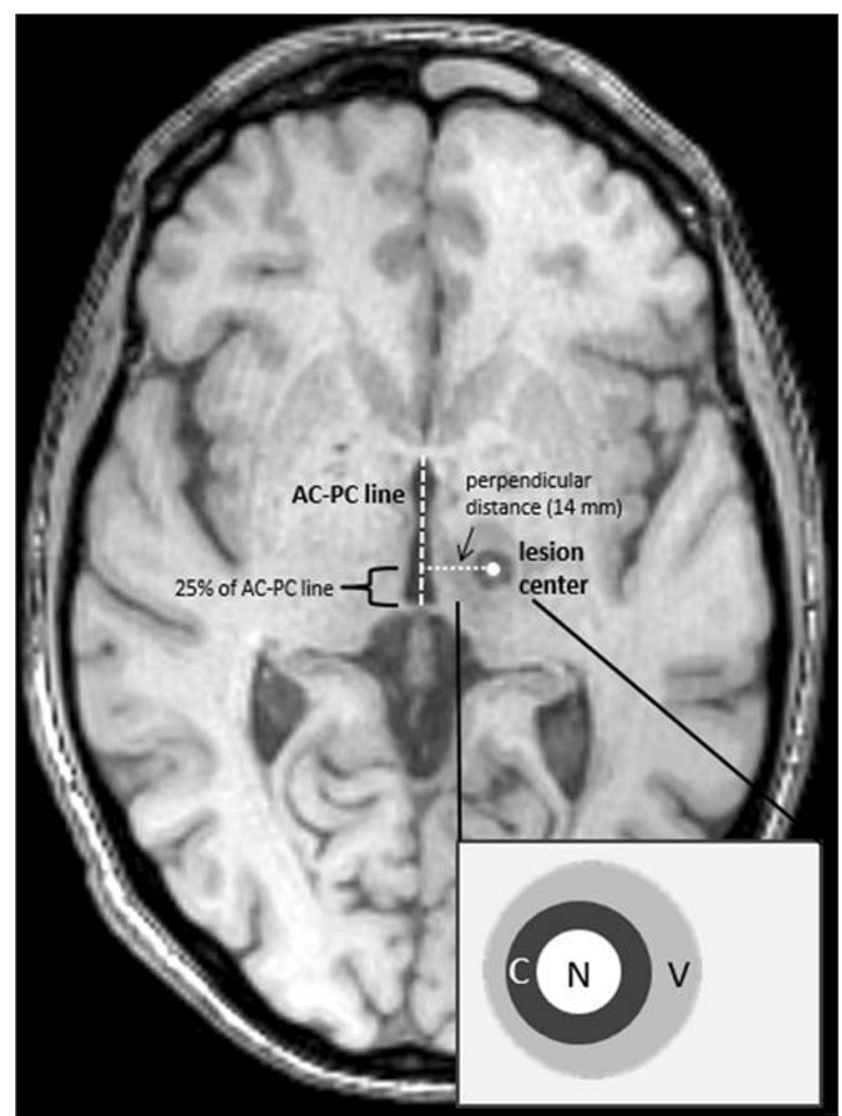

Fig. 1 T1-weighted Vim lesion image on day 3. The left-hemispherical ventral intermediate nucleus (Vim) lesion was expected about $14 \mathrm{~mm}$ left and centrally $1 \mathrm{~mm}$ on the anterior-posterior commissure line (AC-PC line) approximately $25 \%$ of the total distance ventral of the PC. The enlarged scheme illustrates the expected necrotic core $(\mathrm{N})$, the ringshaped cytotoxic oedema zone $(\mathrm{C})$ and the blurred vasogenic oedema (V)

MRgFUS treatment of the Vim (left/right Vim 9/1 patients respectively) with intrainterventional 3-T MRI, and repetitive 3-T MRI as part of the post-interventional monitoring plan.

After written-informed consent, patients had enrolled for MRgFUS treatment and follow-up based on clinical inclusion criteria defined as part of this German Clinical Trials registered and ethically approved study (DRKS00016695). This imaging study follows STROBE guidelines for observational studies.

\section{Imaging follow-up}

The first MRI was performed within $30 \mathrm{~min}$ of the treatment (day 0), while patients were still in the 3-T treatment unit (GE Discovery MR750w, Chicago, IL, USA), using the integrated body coil. The three follow-up MRIs ( 3 days, 1 month, and 6 months after treatment, termed days $3,30,180$ ) were performed with an 8-channel head coil using a different 3-T MRI system (Philips Achieva, TX).

The patients still received dexamethasone ( $4 \mathrm{mg}$ oral, thrice daily from day 0 until day 5) during the day 3 MRI. 


\section{3-T MRI protocol}

The control scan immediately after the intervention consisted of an axial T2-weighted sequence only. In the further follow-up, scans involved a 3D T1-weighted MPRAGE sequence, an axial T2-weighted sequence, a diffusion weighted (DWI), and a susceptibility-weighted (SWI) sequence (Table 1). The SWI image consisted of a phase and a magnitude image of which the magnitude image was used for analysis. Detailed sequence information is given in Table 2.

\section{Image analysis}

Two neuroradiologists (9 and 6 years of experience) performed blinded intensity threshold-based ROI volumetry and additional two-dimensional diameter measurements in all lesions based on T1-weighted, T2-weighted and SWI sequences at all applicable time points on separate work stations (Intellispace 8.0, Philips Healthcare). The volume borders included the presumed cytotoxic oedema zone assuming unsalvageable tissue in this area forming the later cavity.

Deviation between the actual lesion position and the position suggested in the literature was assessed on T1-weighted images on day 3 scans [12]. As already mentioned, the planned Vim centre was defined to be on the level of the AC-PC line and $14 \mathrm{~mm}$ lateral to it. The suggested anteriorposterior lesion position was one quarter of the total AC-PC line distance anterior of the PC (Fig. 1) [12]. For measurements, the lesion centre was considered to be perpendicular to the AC-PC line.

Presence and volume of perilesional oedema were assessed on T2-weighted images.

ROIs were placed in the image slice depicting the largest area of the lesion to measure dynamics of the ADC values over time.

T1-weighted images were visually assessed for the presence of lesions corresponding to lesions with low signal on SWI as an indicator of desoxyhemoglobin or methemoglobin that can be expected from day 3 on [13].

Table 1 Temporal scheme of MRI scans after MRgFUS

\begin{tabular}{lllll}
\hline Sequence & Day 0 & Day 3 & Day 30 & Day 180 \\
\hline T2W & $\mathrm{x}$ & $\mathrm{x}$ & $\mathrm{x}$ & $\mathrm{x}$ \\
SWI & & $\mathrm{x}$ & $\mathrm{x}$ & $\mathrm{x}$ \\
DWI & $\mathrm{x}$ & $\mathrm{x}$ & $\mathrm{x}$ \\
T1w & $\mathrm{x}$ & $\mathrm{x}$ & $\mathrm{x}$ \\
\hline
\end{tabular}

$D W I$ diffusion-weighted imaging, SWI susceptibility-weighted imaging, $T 1 w$ T1-weighted, T2w T2-weighted

\section{Clinical evaluation}

Patients were evaluated by two neurologists ( 28 and 5 years of experience) before MRgFUS and on all days of MRI followup. Clinical symptoms were registered in detail. For comparison with imaging data, however, two classification sets were applied translated from the patients' scores either on the Unified Parkinson's Disease Rating Scale (UPDRS) in PD or the Fahn-Tolosa-Marin Tremor Rating Scale (TRS) in ET:

\section{Clinical rating:}

$1=$ tremor symptoms at least $75 \%$ reduced, $2=$ tremor at least $50 \%$ reduced compared to baseline, $3=$ tremor maximally reduced by $50 \%, 4=$ tremor as strong as before MRgFUS or worse.

\section{Side effects:}

$0=$ none, $1=$ dysaesthesias, $2=$ gait instability, $3=$ dysarthria, $4=$ paresis.

\section{Statistical analysis}

Statistics were performed in SPSS 24.0 using non-parametric testing including paired Wilcoxon tests for inter-time point and sequence comparisons and Spearman rank correlation for clinical outcome versus lesion volume (IBM Corp.). Volume dynamics were compared in absolute values and ratios to a baseline value (defined as $100 \%$ and describing the lesion during its largest volume on average), while all other measurements were compared in absolute values only. Intraclass correlation (two-way mixed effect model) between both neuroradiological readers was determined. Reliability of measurements were considered as poor with an intraclass correlation coefficient (ICC) below 0.5 , as moderate between 0.5 and 0.75 , as good between 0.75 and 0.9 and as excellent above 0.9 [14].

\section{Results}

\section{Lesion location}

Mean AC-PC line length was $25.5 \pm 2.0 \mathrm{~mm}$ (range 22.0 $29.6 \mathrm{~mm}$ ). Clinically determined centres of Vim lesion placement differed from the assumed position of the nucleus as suggested in the literature.

On the right-left axis, mean lesion position was $0.5 \pm$ $1.3 \mathrm{~mm}$ (mean and standard deviation) lateral to the expected $14 \mathrm{~mm}$ (range $1.3 \mathrm{~mm}$ more medial to $3.2 \mathrm{~mm}$ more lateral), and $2.9 \%$ more anterior than the expected $25 \%$ distance from the posterior commissure on the AC-PC line (range -2.3 to 
Table 2 Sequence parameters

\begin{tabular}{|c|c|c|c|c|c|c|c|c|c|}
\hline Sequence & Pulse type & Orientation & $\mathrm{TR}(\mathrm{ms})$ & $\mathrm{TE}(\mathrm{ms})$ & $\begin{array}{l}\text { Reconstructed } \\
\text { voxel size }(\mathrm{mm})\end{array}$ & $\begin{array}{l}\text { Matrix } \\
(\mathrm{mm})\end{array}$ & Slices & $\begin{array}{l}\text { Gap } \\
(\mathrm{mm})\end{array}$ & Scan time \\
\hline Day 0: $\mathrm{T} 2 \mathrm{w}$ & $\mathrm{T} 2$ propeller & Axial & 10,991 & 113 & $0.45 \times 0.45 \times 2$ & $512 \times 512$ & 30 & 0.5 & $5^{\prime} 19^{\prime \prime}$ \\
\hline $\mathrm{T} 2 \mathrm{w}$ & Turbo spin echo & Axial & 13,257 & 90 & $0.94 \times 0.94 \times 1$ & $240 \times 174$ & 140 & 0 & $5^{\prime} 45^{\prime \prime}$ \\
\hline SWI & 3D fast field echo & Axial & 31 & 0 & $0.6 \times 0.6 \times 2$ & $384 \times 316$ & 145 & 0 & $3^{\prime} 57^{\prime \prime}$ \\
\hline DWI & $b$ values $\left(0,500,1000 \mathrm{~s} / \mathrm{mm}^{2}\right)$ & Axial & 2725 & 41 & $1 \times 1 \times 5$ & $128 \times 127$ & 24 & 1 & $0^{\prime} 49^{\prime \prime}$ \\
\hline $\mathrm{T} 1 \mathrm{w}$ & MPRAGE & Sagittal 3D & 7.3 & 3.9 & $1 \times 1 \times 1$ & $256 \times 256$ & 180 & 0 & $4^{\prime} 39^{\prime \prime}$ \\
\hline
\end{tabular}

The total protocol length for follow-up (days 3 to 180) remains below $15 \mathrm{~min}$

$D W I$ diffusion-weighted imaging, MPRAGE magnetization prepared-rapid gradient echo, SWI susceptibility-weighted imaging, $T 1 w$ T1-weighted, $T 2 w$ T2-weighted, $T E$ echo time, $T R$ repetition time

6.9\%; Table 3). Minimum distance between the AC-PC line and the centre of the lesion was $12.7 \mathrm{~mm}$; the maximum distance was $15.7 \mathrm{~mm}$. The lesion centre on the cranio-caudal axis was on average $1.1 \pm 1.2 \mathrm{~mm}$ above the AC-PC line (range $1 \mathrm{~mm}$ below to $3 \mathrm{~mm}$ above; Table 3 ).

\section{Lesion signal intensity and dimensions}

Lesion signal intensities differed per time point and sequence (Table 4). Lesion volumes and diameters were temporally dynamic with significant absolute and relative differences between sequences at all time points (Fig. 2). Mean T2weighted imaging lesion volumes on day 0 were only 42.5 $\pm 20.5 \%$ of the volume they reached on day 3 (Figs. 2 and 3 ).

On day 3 , the day of largest lesion volume, mean lesion volume (T2-weighted images) was $0.4 \pm 0.2 \mathrm{~cm}^{3}$ (minimum $0.2 \mathrm{~cm}^{3}$, maximum $0.8 \mathrm{~cm}^{3}$ ) and $0.3 \pm 0.1 \mathrm{~cm}^{3}$ (minimum $0.1 \mathrm{~cm}^{3}$, maximum $0.7 \mathrm{~cm}^{3}$ ) on SWI images. This volume difference was significant $(p=0.007)$. However, after day 3 , volumes and diameters shrank until end of observation on day 180 with mean SWI-measured lesion volumes being larger than those measured on T2-weighted images (Figs. 2 and 3). Indeed, in $n=4 / 10$ cases, lesions were no longer discernable on T2-weighted images, while the SWI images still showed a clear lesion in all cases.

On day 180 , lesion volumes had shrunk to $6.0 \pm 6.7 \%$ of the peak volume measured on day 3 for T2-based volume measurements $(p=0.005)$ and to $44.1 \pm 42.4 \%$ of the day 3 peak volume on SWI ( $p=0.008)$, leaving a significant difference in volumes also between both sequences performed on day $180(p=0.008)$.

On T1-weighted images, the mean relative volume on day 180 was $8.2 \pm 10.2 \%$ of the volume of day 3 (range 0.0 to $31.6 \%$ ). Additionally, a fading of the lesion was noted with decreasing hypointensity of the lesion in contrast to the adjacent deep grey matter (Table 4, Fig. 4). In consequence, lesions were no longer discernable in $n=4 / 10$ cases on T1weighted images on day 180 .
Lesion diameters were comparable across T1-weighted, T2weighted and SWI sequences $(p=0.78)$, and all reached their maximum volume on day 3. All were below $10 \mathrm{~mm}$ in the long axis and $8 \mathrm{~mm}$ in the short axis except for one patient with a lesion measuring $16.4 \times 10.5 \mathrm{~mm}$ on T2-weighted images (mean $8.4 \pm 2.2 \mathrm{~mm}$ long axis, mean $6.4 \pm 1.6 \mathrm{~mm}$ short axis), who showed clinical side effects (see below). The initial mean diameters $30 \mathrm{~min}$ after therapy were $6.1 \pm 1.9 \mathrm{~mm}$ (long axis) and 4.6 $\pm 1.4 \mathrm{~mm}$ (short axis), and thus more than $20 \%$ shorter in each direction (all measurements on T2-weighted images).

Oedema formation and diffusivity Immediately after MRgFUS therapy, mild oedema formation was observed in only one patient $\left(0.1 \mathrm{~cm}^{3}\right)$. The day 3 control MRI showed oedema in $n=9 / 10$ cases (mean volume $1.5 \pm 0.9 \mathrm{~cm}^{3}$, minimum $0 \mathrm{~cm}^{3}$, maximum $4.0 \mathrm{~cm}^{3}$; Fig. 2b). This fully resolved by day 30 .

Mean oedema volumes measured $3.7 \pm 1.2$ times the lesion itself on day 3 (measured on T2-weighted images). Oedema volume correlated well with lesion size on SWI and T2weighted volumetry $(R=0.824, p=0.003$ and $R=0.707, p=$ 0.022 respectively).

In only 4/9 cases, vasogenic oedema extended beyond the thalamus showed a predilection to extend to the white matter tracts of the internal capsule.

At no point in time, patients showed changes of diffusivity suspicious of infarcts outside the MRgFUS lesion.

Diffusivity dynamics between days 3 and 180 were more complex than volume dynamics (Fig. 3). Between days 3 and 30 , mean ADC dropped $(0.8 \pm 0.1$ to $0.7 \pm$ $\left.0.2 \mathrm{~mm}^{2} / \mathrm{s}, p=0.07\right)$, rising again between days 30 and 180 to $0.9 \pm 0.3 \mathrm{~mm}^{2} / \mathrm{s}(p=0.04)$. The early lesions on day 3 all showed a peculiar ring formation of lower ADC with a centrally higher ADC that corresponded well with the ring formation observed on SWI (Fig. 5). On days 30 and 180 , the lesion was either uniform $(n=9 / 10$ on day $30 ; n=3 / 10$ on day 180 ) or no longer discernable as a lesion on ADC maps at all $(n=1 / 10$ on day $30 ; n=7 /$ 10 on day 180). The span of ADC values measured inside the 


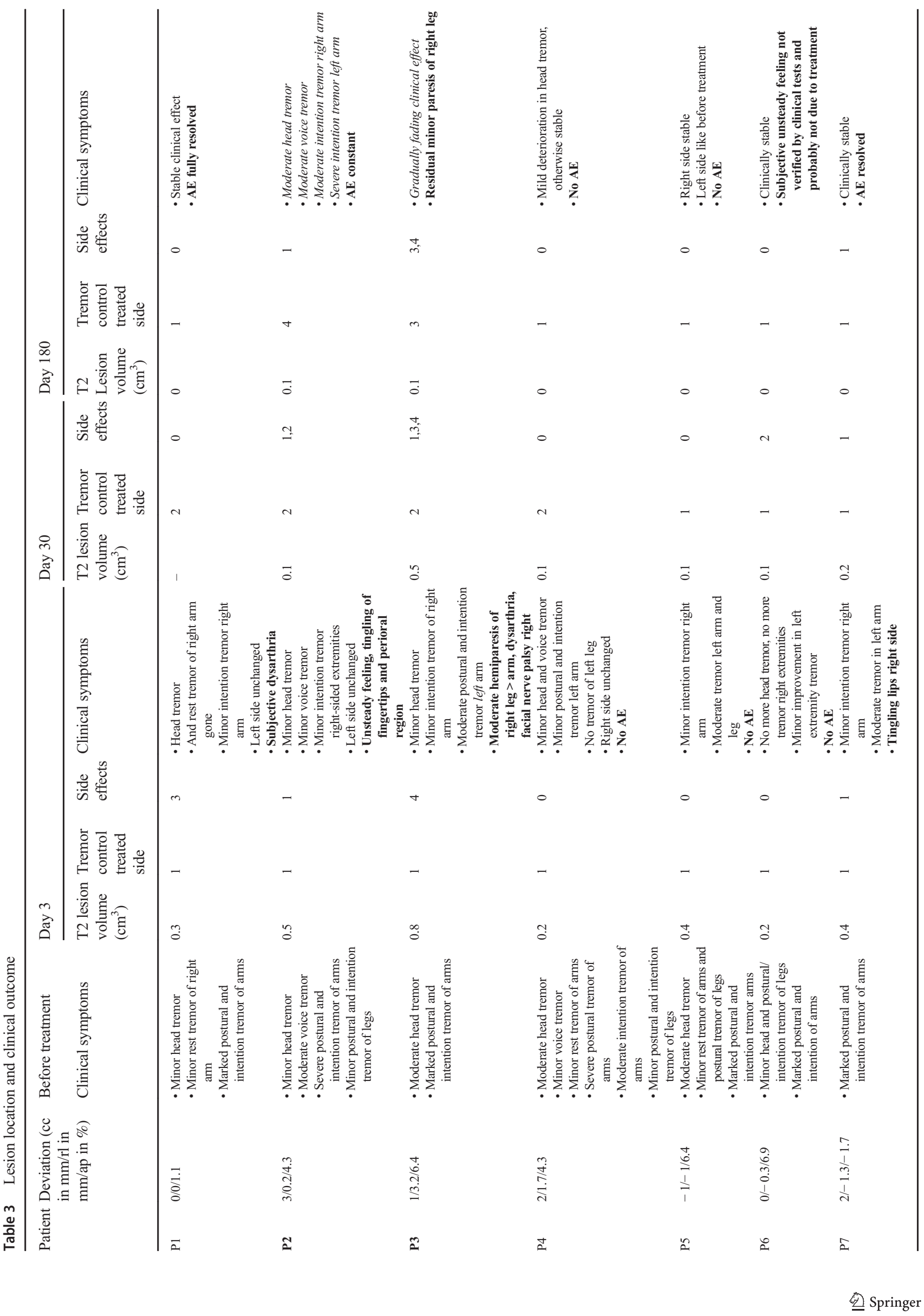




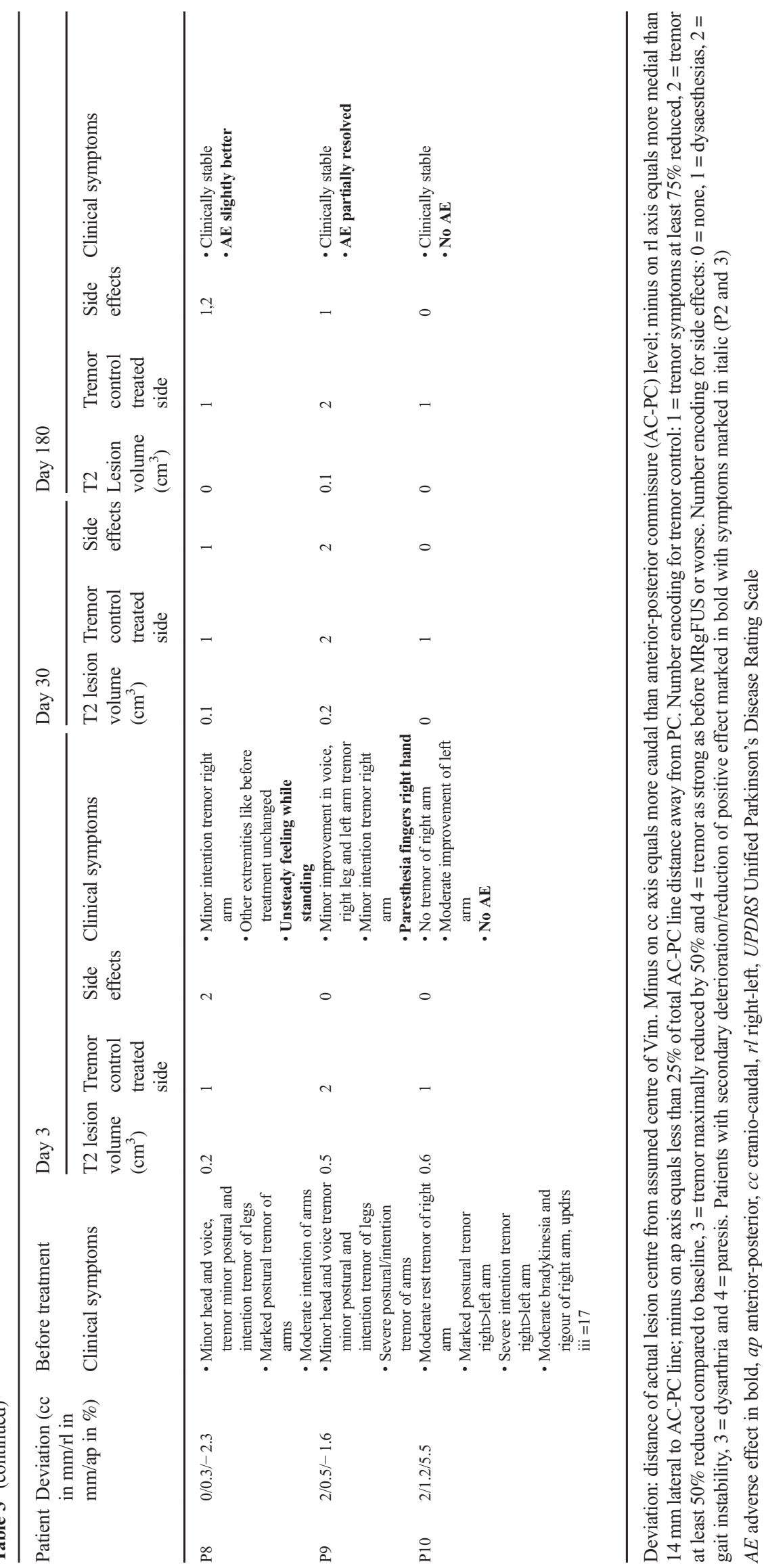


Table 4 Temporal signal intensity evolution of lesions after MRgFUS in comparison with surrounding thalamus

\begin{tabular}{lllll}
\hline Sequence & Day 0 & Day 3 & Day 30 & Day 180 \\
\hline T2w & Rim: hyper & All hyper & All hyper & All hyper \\
& Centre: hypo & Rim: hypo & Rim: hypo & All hypo \\
SWI & $\mathrm{n} / \mathrm{a}$ & Centre: hyper & All high ADC & All intermediate or slightly elevated ADC \\
& $\mathrm{n} / \mathrm{a}$ & Rim: low ADC & All mildly hypo & All mildly hypo to iso \\
DWI & $\mathrm{n} / \mathrm{a}$ & All hypo & &
\end{tabular}

$A D C$ apparent diffusion coefficient, DWI diffusion-weighted imaging, SWI susceptibility-weighted imaging, T1w T1-weighted, T2w T2-weighted, centre lesion centre, hyper hyperintense in comparison with healthy thalamus, hypo hypointense in comparison with healthy thalamus, iso isointense in comparison with healthy thalamus, rim outer lesion rim

lesion hence was larger on day 3 due to differences measured in the ring formation than on day 30 (Fig. 3).

\section{Technical data and clinical correlation}

Table 5 illustrates the technical parameters to achieve a lesion for each of the patients. There was no significant correlation between initial lesion volume and clinical improvement $(p=$ 0.99 for all-over motor improvement and $p=0.77$ for tremor reduction on the treated side; Table 3; Fig. 6a, b).

Clinical effects remained stable in the majority of patients during the first 180 days $(p=0.43$ all-over motor skills; $p=$
$0.29)$, despite rare secondary deterioration of all-over motor skills $(n=2)$ or tremor on the treated side $(n=2$; Fig. 6 c, d).

Greater lesion shrinkage was not correlated with allover motor improvement $(p=0.57)$, but with dynamics of tremor improvement of the treated side clinical outcome ( $p=0.01, R=0.76$; Fig. 6e). One patient (patient $3)$, whose lesion was particularly far lateral from the AC-PC line $(17.2 \mathrm{~mm})$ and showed extensive oedema (day 3 maximum $4.0 \mathrm{~cm}^{3}$ ), developed moderate hemiparesis with not onlt secondary improvement regaining walking capacity, but also secondary deterioration of the therapeutic effect (Table 3).

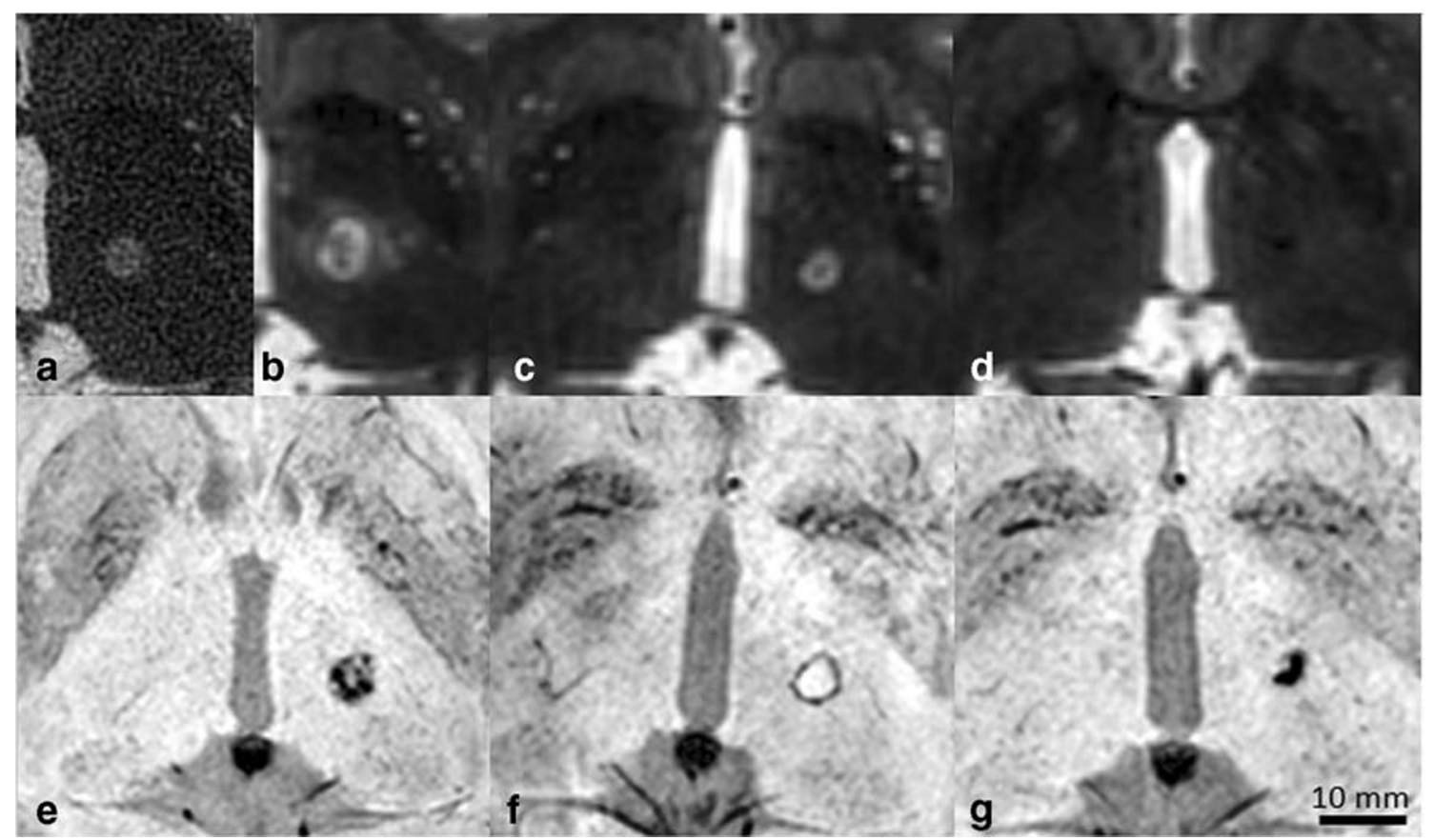

Fig. 2 Lesion dynamics at 3-T on T2-weighted and susceptibilityweighted images over time. a-d T2-weighted images and $\mathbf{e}-\mathbf{g}$ susceptibility-weighted images. a Thirty minutes after therapy, b 3 days, c 30 days and $\mathbf{d} 180$ days after therapy. e Three days, f 30 days and $\mathbf{g}$ 180 days after therapy. Note how the lesion first increases in size during the first 3 days (a vs. b), while it has completely vanished half a year after therapy on T2-weighted images and yet remains distinctly visible on susceptibility-weighted images. Image b also depicts the oedema surrounding the core lesion separated by a fine hypointense dark rim. The noisy aspect of image a is due to the distant MRI-integrated body coil used, while the patient was still wearing the treatment helmet 
Fig. 3 Temporal evolution of ventral intermediate nucleus lesion volumes and corresponding apparent diffusion coefficients (ADCs).

Dimensionless relative values are defined as relative to the volume measured on day 3 by building the ration $\left(x_{t} / x_{d}=3\right)$. a Relative lesion volume dynamics measured on T2-weighted images in 10 patients. b Absolute lesion volumes on T2-weighted images marked by mean and 5th to 95 th percentiles. $\mathbf{c}$ Relative lesion volume dynamics measured on susceptibility-weighted images. d Absolute lesion volumes on susceptibility images marked by mean and $5^{\text {th }}$ to $95^{\text {th }}$ percentiles. $\mathrm{e}$ Absolute ADC values at different time points stated as mean and $5^{\text {th }}$ to $95^{\text {th }}$ percentiles. $f$ The span of ADC values describes the difference between the minimum and maximum ADC measured in a lesion region of interest at a point of time. D0: day 0 MRI $30 \mathrm{~min}$ after therapy, D3: MRI on day 3 after therapy, D30: MRI 30 days after therapy, D180: MRI

180 days after therapy relative T2-volume dynamics

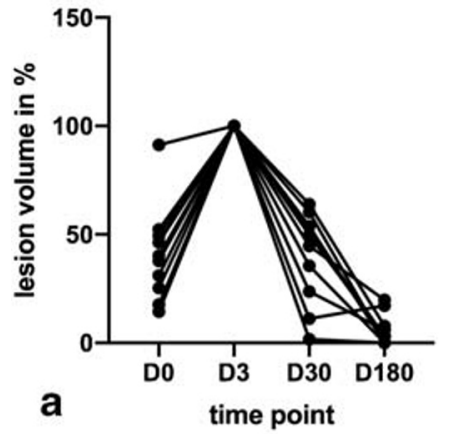

relative SWI-volume dynamics

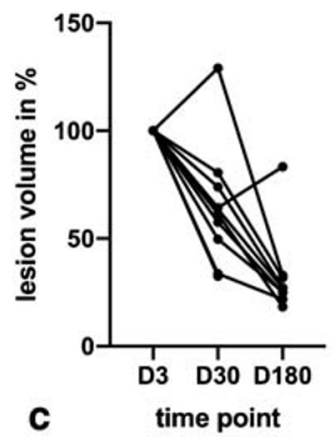

ADC value dynamics

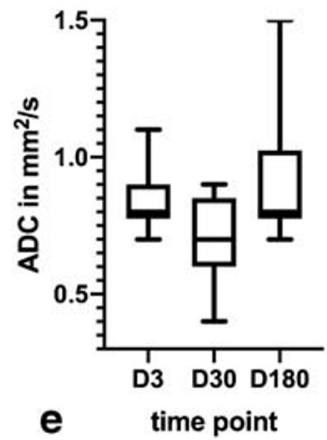

absolute lesion volume T2 dynamics

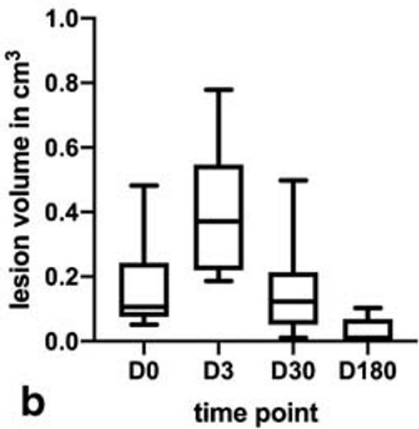

absolute lesion volume SWI dynamics

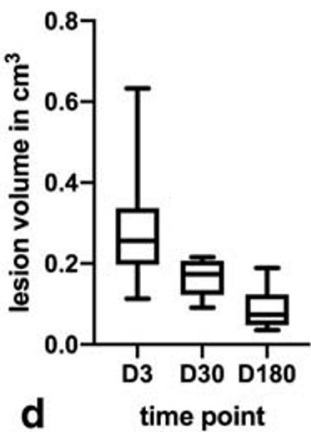

span of ADC values in lesion

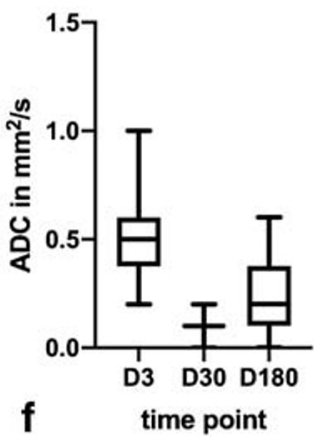

\section{Interobserver reliability}

Interobserver reliability lesion measurements were excellent for T2-weighted (ICC 0.99 confidence interval [0.99, 0.99]), T1-weighted (ICC $0.99[0.99,0.99]$ ) as well as for oedema volumes (ICC $0.92[0.90,0.94])$ and good for SWI (ICC 0.89 $[0.75,0.95])$. Reliability of ADC measurements was excellent (ICC 0.96 [0.92, 0.98]). Lesion diameter measurements were also reliable for T2-weighted, SWI and T1-weighted with ICCs of 0.99 .
Fig. 4 Fading of the MRgFUS lesion on T1-weighted images. While on SWI and T2-weighted images shrinkage of the lesion was noted, the lesion rather faded in signal intensity compared with the surrounding brain tissue. a Day 3, b day 30 (black arrows indicating lesion margins) and $\mathbf{c}$ "vanished" lesion on day 180

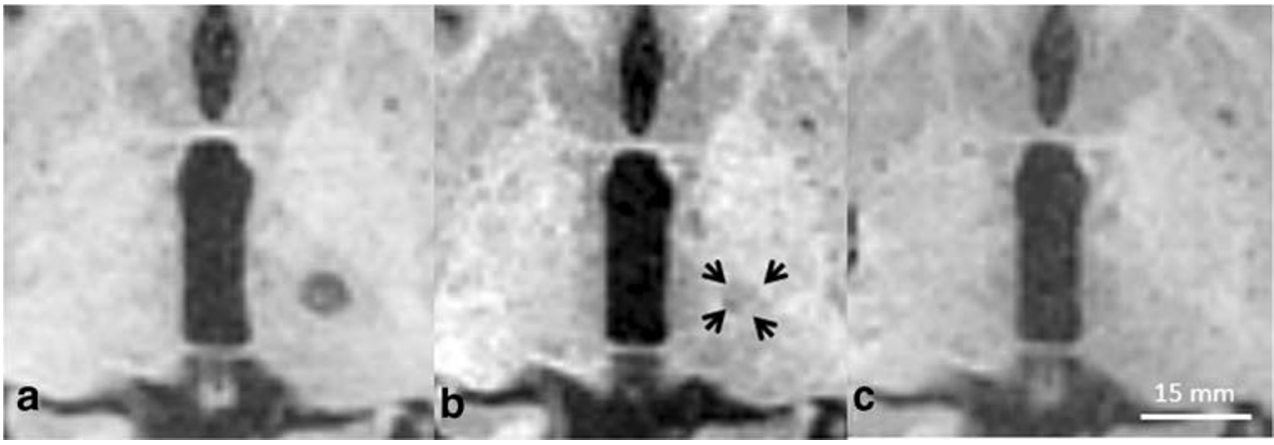




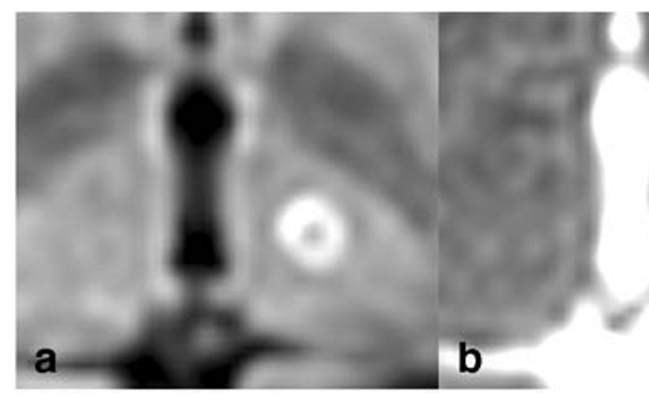

Fig. 5 Lesion presentation on diffusion-weighted images on day 3 after therapy and corresponding susceptibility-weighted image. a $b=1000 \mathrm{~s} /$ $\mathrm{mm}^{2}$ diffusion-weighted image depicting a characteristic bright ring formation inside the lesion. $\mathbf{b}$ According to the low intensity on the apparent

Discussion This study elaborated the evolution of imaging features of MRgFUS thalamic lesions. MRgFUS lesions shrink within the first 6 months after therapy. Lesions may become invisible on DWI, T1- and T2-weighted images, while as a main finding, they always remained identifiable on SWI. DWI is excellent to reveal the borders of the cytotoxic oedema right after therapy, but resolves within 1 month. Our data further suggests that while there seems to be no association between lesion volume and clinical improvement in the acute phase, there are signs that dynamics of lesion shrinkage can be associated with dwindling tremor improvement as is suggested by better tremor improvement of the treated side being correlated to less lesion volume reduction.

The initial enlargement of the MRgFUS lesions between days 0 and 1 with secondary shrinkage of lesion volume on $\mathrm{T} 2$-weighted images is a common feature $[15,16]$. Our findings suggest that $\mathrm{T} 2$-weighted images can be inadequate to assess MRgFUS already after 1 month due to complete disappearance of the lesion. As T2-weighted images may return to normal after 1 month, these seem inadequate for longer follow-up studies. However, they are primarily useful in the

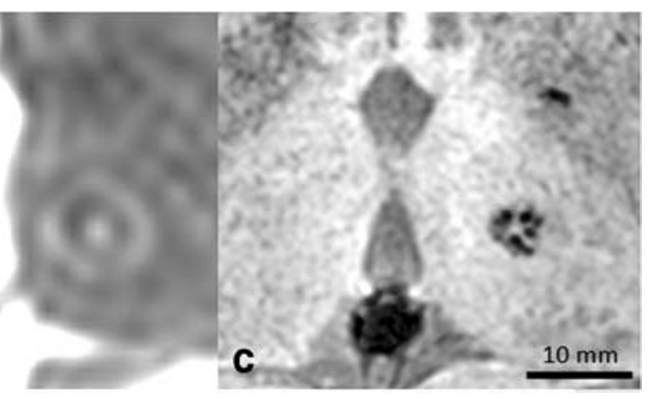

diffusion coefficient map, the lesion has restricted diffusivity. $\mathbf{c}$ The ring shape corresponds well to the speckled ring shape of the lesion observed on susceptibility-weighted images of the same person

first days after MRgFUS therapy to assess oedema formation and approximate lesion extent.

It is not surprising that lesion volumes differ significantly between T1- and T2-weighted studies [3], and also when comparing SWI and T2-weighted images as in this study, as the ultrasound effect on the lesion is not uniform creating variable tissue changes that result in likewise variable alteration in $\mathrm{T} 1$ and T2 signal. SWI is mainly used to identify cerebral haemorrhage and discriminate it from calcification, and we do know from clinical experience that SWI has the technical capacity to detect very subtle hemosiderin remnants where $\mathrm{T} 1$ and T2-weighted sequences of a similar resolution do not show any traces [17]. The outstanding lesion persistence of low signal on SWI compared with other sequences and also T2* GRE is well documented for post-traumatic as well as subarachnoid haemorrhage lesions [18, 19]. All lesions in our study showed a low signal on SWI representing coagulation necrosis/infarct-like thermal tissue alterations as demonstrated histologically by Elias et al. in a porcine model [20]. The most likely explanation is the focal destruction of erythrocytes in the MRgFUS lesion centre. On the other hand, due to these
Table 5 Individual patient treatment course

\begin{tabular}{llllll}
\hline Patient & Diagnosis & $\begin{array}{l}\text { Number of test } \\
\text { sonications }\end{array}$ & $\begin{array}{l}\text { Number of therapeutic } \\
\text { sonications }\end{array}$ & $\begin{array}{l}\text { Highest achieved } \\
\text { temperature }\left({ }^{\circ} \mathrm{C}\right)\end{array}$ & $\begin{array}{l}\text { Energy } \\
\text { delivered (W) }\end{array}$ \\
\hline 1 & ET & 7 & 4 & 62 & 850 \\
2 & ET & 10 & 5 & 61 & 756 \\
3 & ET & 8 & 9 & 60 & 846 \\
4 & ET & 9 & 5 & 58 & 894 \\
5 & ET & 11 & 9 & 61 & 900 \\
6 & ET & 5 & 5 & 64 & 849 \\
7 & ET & 7 & 4 & 65 & 929 \\
8 & ET & 7 & 4 & 61 & 1099 \\
9 & ET & 9 & 4 & 62 & 1001 \\
10 & PD & 4 & 3 & 59 & 900 \\
\hline
\end{tabular}

The energy applied represents the energy truly delivered into the tissue, not the a priori determined value $E T$ essential tremor, $P D$ Parkinson disease 


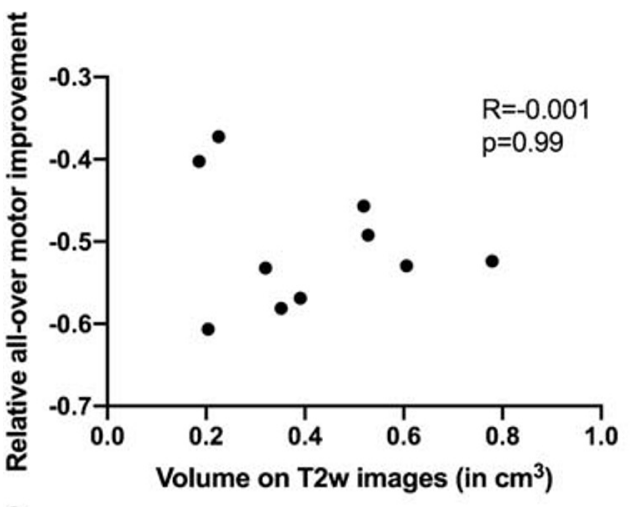

a

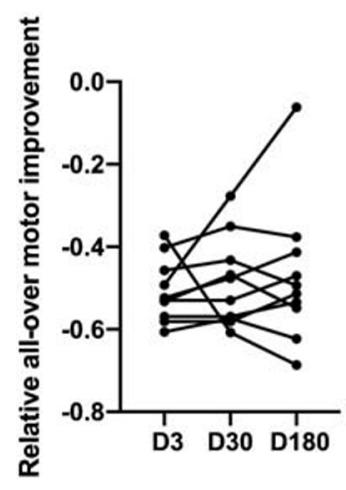

C

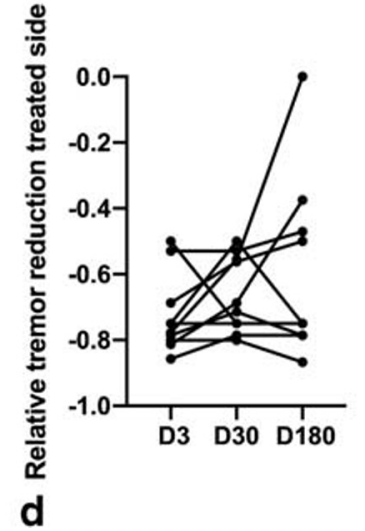

Fig. 6 a Reduction of motor symptoms in general motor task testing as opposed to baseline (baseline score minus post-treatment score/baseline score) correlated with lesion volume both on day 3. b Reduction of tremor symptoms on the treated side as opposed to baseline (baseline score minus post-treatment score/baseline score) correlated with lesion volume both on day 3. c Relative reduction of motor symptoms in general motor task testing over time. d Relative reduction of tremor symptoms on the

low signal lesions, it can be problematic to identify true intralesional bleeds deriving from vessel damage within this zone with SWI as they would appear the same and are therefore camouflaged. Haemorrhage after cerebral MRgFUS is however rare ( $n=0 / 10$ in this study). Yet, single reports of microbleeds exist with haemorrhage seen as bright spots from methemoglobin after day 3 on T1-weighted images, which can be used for bleed verification [21].

We consistently observed a fading of decreasingly hypointense lesions on T1-weighted images on day 30 . Wintermark et al. disparately infrequently identified bright ring lesions on this day [4]. The temporal dynamics towards an eventual fading of lesions on T1-weighted images is however identical. This fading on T1-weighted images may be explained by biochemical changes, e.g. protein degradation and iron-containing particle removal, in the composition of the lesion over time, which shortens $\mathrm{T} 1$ relaxation time. The phenomenon of temporal alteration in $\mathrm{T} 1$ signal was recently published in a longitudinal case report on radiation necrosis describing significant alterations in $\mathrm{T} 1$ relaxation time and
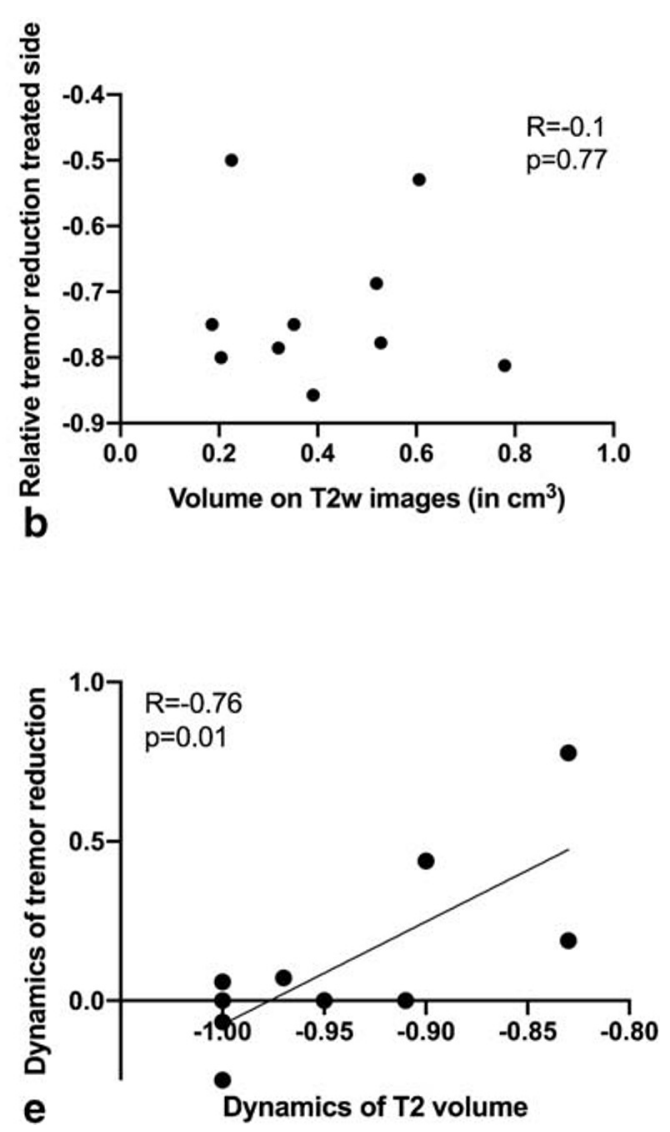

treated side over time. e Dynamics of relative changes in tremor reduction (day 180 versus day 3 ) as opposed to dynamics in $\mathrm{T} 2$ volume between day 180 and day 3 . $A-1.00$ on the $x$-axis represents a lesion that is no longer discernable. D3: MRI on day 3 after therapy, D30: MRI 30 days after therapy, D180: MRI 180 days after therapy, T2w: T2-weighted volumetry

SWI aspect over a period of 52 months [22]. However, it does not explain the difference in intensity on day 30 between our cohorts and in part that of Wintermark. The radiologist must bear mind that effects other than T1 shortening and secondary fading may be observed.

The imaging aspect of MRgFUS lesions seen on SWI over time suggests a condensation of necrotic tissue elements from a ring-like shape (or spherical in 3D) to a contracted granular end-stage lesion, which shows parallels to treatment of the VIM using radiofrequency probes in the past [23]. DWI may indirectly confirm this as according to our study, a ring-shaped diffusion-restricted structure representing cytotoxic oedema matched excellently with the ring structure observed in SWI on day 3. Again, similar to T2-weighted imaging, DWI was only useful during the first days after MRgFUS to show the intralesional cytotoxic oedema.

Vasogenic oedema was also a short-term phenomenon and - with one exception - not present before day 3 and no more observed beyond day 30 . Although only present in one case in our study, there was a predilection of oedema to follow 
white matter structures along the internal capsule and hypothalamic tracts with relative sparing of deep grey matter structures, which is anatomically plausible due to water following the anisotropic lead structures set by white matter bundles.

Clinically based lesion positions differed slightly from the assumed position of the Vim in our study, an observation that had been reported earlier based on DTI data [24]. All-over analysis in this study showed a non-significant reduction of treatment effects until 6 months after MRgFUS. However, lesions with larger relative reduction in volume within 6 months correlated with a more prominent recurrence of tremor. It can be speculated that in these patients, at least some of the initial effect was due to lesional oedema. These two observations are in coherence with a 2-year follow-up study in ET patients, that similar to our study did not identify any delayed effects [11], but partially stands against findings of Wintermark et al., who showed a clear decline of clinical effect with declining oedema and lesion size [4]. Even in retrospect, it remains unclear why two of our patients showed a measurable deterioration of symptom control, i.e. secondary treatment failure. There was no difference in distance between real and expected target or lesion volume decline in those two compared with the others. Lesion size and presence of oedema were indeed remarkably larger in patient 3 , who also had substantial side effects. However, this is not true for patient 2 and does also not explain a secondary reduction of effect. Another aspect can be the technical performance of the treatment. Still no differences regarding the number of test sonications, peak temperatures or energy applied can be identified in those patients with partial secondary treatment failure. These technical parameters are however anyhow highly individual for the patient and the lesion and depend on multiple factors such as the skull density score, previous sonications and temperature evolution. Highly interesting is also the positive therapeutic effect to the non-treated side after unilateral MRgFUS, which in some cases was permanent in our patients. The underlying reason is most likely an effect on crossing fibres to the contralateral hemisphere. The phenomenon was previously described for MRgFUS and deep brain stimulation alike, but still needs further scientific exploration, e.g. with fibre tracking [25].

While our study is based upon a very limited number of patients, its results are in line with previous findings. The diversity of MRgFUS techniques remains however an unknown influential factor in this context.

In conclusion, radiologists should be aware that the follow-up of MRgFUS lesions shows an ageing and especially shrinkage process and therefore require different high-resolution sequences for follow-up. Lesions can be observed longer on SWI than on other sequences. The clinical effect however outlives the Vim lesion itself, such that it remains questionable, if shrinkage dynamics have any association with the clinical outcome. In consequence, necessity and interpretation of long-term follow-up MRI in MRgFUS patients is disputable.
Acknowledgements Open Access funding provided by Projekt DEAL.

Author contributions Vera Keil and Claus Pieper designed the concept and first draft of this manuscript. All other coauthors contributed by writing and commenting based on the draft. Veronika Purrer and Ullrich Wüllner delivered clinical data. Simon Grötz, Claus Pieper and Vera Keil performed the procedures together with Valeri Borger and Ullrich Wüllner.

Funding information This study was funded by a Dt. Forschungsgemeinschaft project grant (no. 328023777).

\section{Compliance with ethical standards}

Competing interests The authors declare that they have no conflict of interest.

Ethics approval All procedures performed in studies involving human participants were in accordance with the ethical standards of the institutional and/or national research committee and with the 1964 Helsinki declaration and its later amendments or comparable ethical standards. This is a registered study: DRKS00016695 that followed STROBE guidelines.

Consent to participate Informed consent was obtained from all individual participants included in the study.

Consent for publication All coauthors approved of this manuscript submission for publication.

Open Access This article is licensed under a Creative Commons Attribution 4.0 International License, which permits use, sharing, adaptation, distribution and reproduction in any medium or format, as long as you give appropriate credit to the original author(s) and the source, provide a link to the Creative Commons licence, and indicate if changes were made. The images or other third party material in this article are included in the article's Creative Commons licence, unless indicated otherwise in a credit line to the material. If material is not included in the article's Creative Commons licence and your intended use is not permitted by statutory regulation or exceeds the permitted use, you will need to obtain permission directly from the copyright holder. To view a copy of this licence, visit http://creativecommons.org/licenses/by/4.0/.

\section{References}

1. Zaaroor M, Sinai A, Goldsher D, Eran A, Nassar M, Schlesinger I (2018) Magnetic resonance-guided focused ultrasound thalamotomy for tremor: a report of 30 Parkinson's disease and essential tremor cases. J Neurosurg 128(1):202-210. https://doi. org/10.3171/2016.10.JNS16758

2. Gallay MN, Moser D, Federau C, Jeanmonod D (2019) Radiological and thermal dose correlations in pallidothalamic tractotomy with MRgFUS. Front Surg 6:28. https://doi.org/10.3389/fsurg.2019.00028

3. Jones RM, Kamps S, Huang Y, Scantlebury N, Lipsman N, Schwartz ML et al (2019) Accumulated thermal dose in MRI-guided focused ultrasound for essential tremor: repeated sonications with low focal temperatures. J Neurosurg:1-8. https://doi.org/10.3171/2019.2. JNS182995

4. Wintermark M, Druzgal J, Huss DS, Khaled MA, Monteith S, Raghavan P, Huerta T, Schweickert LC, Burkholder B, Loomba JJ, Zadicario E, Qiao Y, Shah B, Snell J, Eames M, Frysinger R, 
Kassell N, Elias WJ (2014) Imaging findings in MR imagingguided focused ultrasound treatment for patients with essential tremor. AJNR Am J Neuroradiol 35(5):891-896. https://doi.org/ 10.3174/ajnr.A3808

5. Elias WJ, Lipsman N, Ondo WG, Ghanouni P, Kim YG, Lee W, Schwartz M, Hynynen K, Lozano AM, Shah BB, Huss D, Dallapiazza RF, Gwinn R, Witt J, Ro S, Eisenberg HM, Fishman PS, Gandhi D, Halpern CH, Chuang R, Butts Pauly K, Tierney TS, Hayes MT, Cosgrove GR, Yamaguchi T, Abe K, Taira T, Chang JW (2016) A randomized trial of focused ultrasound thalamotomy for essential tremor. N Engl J Med 375(8):730-739. https://doi.org/10. 1056/NEJMoa1600159

6. Bond AE, Shah BB, Huss DS, Dallapiazza RF, Warren A, Harrison MB, Sperling SA, Wang XQ, Gwinn R, Witt J, Ro S, Elias WJ (2017) Safety and efficacy of focused ultrasound thalamotomy for patients with medication-refractory, tremor-dominant Parkinson disease: a randomized clinical trial. JAMA Neurol 74(12):14121418. https://doi.org/10.1001/jamaneurol.2017.3098

7. Jung NY, Park CK, Chang WS, Jung HH, Chang JW (2018) Effects on cognition and quality of life with unilateral magnetic resonanceguided focused ultrasound thalamotomy for essential tremor. Neurosurg Focus 44(2):E8. https://doi.org/10.3171/2017.11. FOCUS17625

8. Tian Q, Wintermark M, Jeffrey Elias W, Ghanouni P, Halpern CH, Henderson JM, Huss DS, Goubran M, Thaler C, Airan R, Zeineh M, Pauly KB, McNab J (2018) Diffusion MRI tractography for improved transcranial MRI-guided focused ultrasound thalamotomy targeting for essential tremor. Neuroimage Clin 19: 572-580. https://doi.org/10.1016/j.nicl.2018.05.010

9. Gallay MN, Moser D, Jeanmonod D (2018) Safety and accuracy of incisionless transcranial MR-guided focused ultrasound functional neurosurgery: single-center experience with 253 targets in 180 treatments. J Neurosurg:1-10. https://doi.org/10.3171/2017.12. JNS172054

10. Fishman PS, Elias WJ, Ghanouni P, Gwinn R, Lipsman N, Schwartz M, Chang JW, Taira T, Krishna V, Rezai A, Yamada K, Igase K, Cosgrove R, Kashima H, Kaplitt MG, Tierney TS, Eisenberg HM (2018) Neurological adverse event profile of magnetic resonance imaging-guided focused ultrasound thalamotomy for essential tremor. Mov Disord 33(5):843-847. https://doi.org/10. 1002/mds.27401

11. Chang JW, Park CK, Lipsman N, Schwartz ML, Ghanouni P, Henderson JM, Gwinn R, Witt J, Tierney TS, Cosgrove GR, Shah BB, Abe K, Taira T, Lozano AM, Eisenberg HM, Fishman PS, Elias WJ (2018) A prospective trial of magnetic resonance-guided focused ultrasound thalamotomy for essential tremor: results at the 2-year follow-up. Ann Neurol 83(1):107-114. https://doi.org/10. 1002/ana.25126

12. Sakas DE, Kouyialis AT, Boviatsis EJ, Panourias IG, Stathis P, Tagaris G (2007) Technical aspects and considerations of deep brain stimulation surgery for movement disorders. Acta Neurochir Suppl 97(Pt 2): 163-170. https://doi.org/10.1007/978-3-211-33081-4_18

13. Bradley WG Jr (1993) MR appearance of hemorrhage in the brain. Radiology 189(1):15-26. https://doi.org/10.1148/radiology.189.1. 8372185

14. Koo TK, Li MY (2016) A guideline of selecting and reporting intraclass correlation coefficients for reliability research. J Chiropr Med 15(2):155-163. https://doi.org/10.1016/j.jcm.2016.02.012
15. Jung HH, Chang WS, Rachmilevitch I, Tlusty T, Zadicario E, Chang JW (2015) Different magnetic resonance imaging patterns after transcranial magnetic resonance-guided focused ultrasound of the ventral intermediate nucleus of the thalamus and anterior limb of the internal capsule in patients with essential tremor or obsessivecompulsive disorder. J Neurosurg 122(1):162-168. https://doi.org/ 10.3171/2014.8.JNS132603

16. Harary M, Essayed WI, Valdes PA, McDannold N, Cosgrove GR (2018) Volumetric analysis of magnetic resonance-guided focused ultrasound thalamotomy lesions. Neurosurg Focus 44(2):E6. https://doi.org/10.3171/2017.11.FOCUS17587

17. Deistung A, Schweser F, Wiestler B, Abello M, Roethke M, Sahm F, Wick W, Nagel AM, Heiland S, Schlemmer HP, Bendszus M, Reichenbach JR, Radbruch A (2013) Quantitative susceptibility mapping differentiates between blood depositions and calcifications in patients with glioblastoma. PLoS One 8(3):e57924. https://doi. org/10.1371/journal.pone.0057924

18. Inoue $\mathrm{T}$, Takada $\mathrm{S}$, Shimizu $\mathrm{H}$, Niizuma $\mathrm{K}$, Fujimura $\mathrm{M}$, Sato $\mathrm{K}$, Endo H, Tominaga T (2013) Signal changes on T2*-weighted magnetic resonance imaging from the acute to chronic phases in patients with subarachnoid hemorrhage. Cerebrovasc Dis 36(5-6):421-429. https://doi.org/10.1159/000355897

19. Schelhorn J, Gramsch C, Deuschl C, Quick HH, Nensa F, Moenninghoff C, Schlamann M (2015) Intracranial hemorrhage detection over time using susceptibility-weighted magnetic resonance imaging. Acta Radiol 56(12):1501-1507. https://doi.org/ $10.1177 / 0284185114559958$

20. Elias WJ, Khaled M, Hilliard JD, Aubry JF, Frysinger RC, Sheehan JP, Wintermark M, Lopes MB (2013) A magnetic resonance imaging, histological, and dose modeling comparison of focused ultrasound, radiofrequency, and gamma knife radiosurgery lesions in swine thalamus. J Neurosurg 119(2):307-317. https://doi.org/10. 3171/2013.5.JNS122327

21. Weidman EK, Kaplitt MG, Strybing K, Chazen JL (2019) Repeat magnetic resonance imaging-guided focused ultrasound thalamotomy for recurrent essential tremor: case report and review of MRI findings. J Neurosurg:1-6. https://doi.org/10.3171/2018. 10.JNS181721

22. Wiggermann V, Lapointe E, Litvin L, Graf C, Hernandez-Torres E, McKenzie M et al (2019) Longitudinal advanced MRI case report of white matter radiation necrosis. Ann Clin Transl Neurol 6(2): 379-385. https://doi.org/10.1002/acn3.704

23. Tomlinson FH, Jack CR Jr, Kelly PJ (1991) Sequential magnetic resonance imaging following stereotactic radiofrequency ventralis lateralis thalamotomy. J Neurosurg 74(4):579-584. https://doi.org/ 10.3171/jns.1991.74.4.0579

24. Sammartino F, Krishna V, King NK, Lozano AM, Schwartz ML, Huang Y, Hodaie M (2016) Tractography-based ventral intermediate nucleus targeting: novel methodology and intraoperative validation. Mov Disord 31(8):1217-1225. https://doi.org/10.1002/mds.26633

25. Jameel A, Bain P, Nandi D, Jones B, Kirmi A, Gedroyc WM (2019) A deeper impact - using MRgFUS for the treatment of essential tremor targeting both thalamic vim and the subthalamic Zona Incerta. RSNA Chicago, I1/USA, presented Dec 4, 2019. Abstract: SSK16-06

Publisher's note Springer Nature remains neutral with regard to jurisdictional claims in published maps and institutional affiliations. 